\title{
IS THERE ALWAYS A POSITIVE RELATIONSHIP BETWEEN WORKPLACE DIVERSITY AND ORGANIZATIONAL PERFORMANCE, OR DOES DIVERSITY FATIGUE IMPLY A SUPPRESSING EFFECT?
}

Panteha Farmanesh, Asim Vehbi, Pouya Zargar, Arman Sousan, Feyza Bhatti

\section{Abstract}

Performance of employees has been a vital matter for all organizations regardless of their sector. As organizations become more diverse, maintaining high performance becomes a challenge. This study examines the relationship between workforce diversity and organizational performance in educational sector of Cyprus through moderating effect of diversity fatigue. Mixed Method is used for the purposes of this study to analyze data from university academic staff, through survey and senior-level interviews (semi-structured). Qualitative measures were used to develop dimensions for diversity fatigue, which further were tested through quantitative approach. Results imply that extent of diversity fatigue can suppress the relationship between overall performance and workforce diversity, which is positive and significant prior to interaction of fatigue. Furthermore, our study expands the literature regarding the topic within educational sector. Managers can have an enhanced decision-making process regarding diverse workforce and degree of fatigue, which yields in a higher performance level for the firm.

Keywords: Workplace Diversity, Diversity Fatigue, Overall Performance, Academia

JEL Classification: L25, M14

\footnotetext{
Panteha Farmanesh, PhD (corresponding author) Associate Professor

Head of International Business Management

Faculty of Business and Economics

Girne American University

Email: pantehafarmanesh@gau.edu.tr

Address: University Drive, Karmi Campus,

Karaoglanoglu, Kyrenia, North Cyprus, 99428

Asim Vehbi, PhD

Associate Professor

Vice Rector

Faculty of Business and Economics

Aarkin University of Creative Arts and Design

Email: asim.vehbi@arucad.edu.tr
}

\section{Pouya Zargar, PhD Candidate Research Assistant \\ Faculty of Business and Economics \\ Girne American University \\ Email: p.zargar@gmail.com}

Arman Sousan, PhD Candidate Faculty of Business and Economics Girne American University Email:arman_soosan66@yahoo.com
Feyza Bhatti, PhD
Assistant Professor
Vice Dean
Faculty of Business and Economics
Girne American University
Email: feyzabhatti@gau.edu.tr 


\section{INTRODUCTION}

To accomplish business success there are a number factors that are crucial, and the diversity of employees is an element, which with careful management and accreditation can stimulate improved success (Richard and Johnson 2001). As a result of the number of migrant workers and the ever evolving globalization, utilization of diversity can validate the potential growth of businesses. As universities around the world are encouraging overseas students, the demand for different cultures to be present during educational programs has increased. However, it is important to note that the concept of diversification within a company is a sensitive matter and cannot be expected to flourish in every context. The recruitment of global staff, who can accommodate the influx of international students is essential within a university campus and therefore, diversity is integrated from the outset. There is a general agreement that continuous management and active encouragement inside an organization is essential. This highlights the need to accommodate and explore relevant and crucial aspects of requirements on parties concerned (i.e. agents) (McKay, Avery, and Morris 2009). Hence, it is vital to highlight the delicate process of selection and recruitment regarding diverse workforce, which is to be intact with university goals as well as its current atmosphere. Understanding underlying effects and influential factors alongside proper management is of necessity if an organization is to increase its diversity.

A number of features should be included/mentioned when exploring the concept of diversity (e.g. sex, age, ethnicity, level of education, personal history, and profession). Research by Kreitz (2008) described diversity as the differences that are present and exist that distinguish individuals from one another. Factors of diversity can be from any number of personal traits, whether obvious or concealed beneath the surface, and can be past, present or future related. Our study focuses on the extent of which a diverse workforce can contribute to overall performance of an organization (universities) through moderating effect of diversity fatigue that is an emotional state of employees. These concepts are further explained in detail. This specific research focuses on these factors included in university environment. Additionally, our study takes an already diverse environment into account for conduction of this research as diversity is implied within the universities of Northern Cyprus and particularly, those located in Kyrenia.

Having a workforce, which includes greater diversity, and encourages a global awareness, leads to increased competitiveness in the market. Furthermore, the employment of staff with diversity can lead the organization towards improved services. Integration of these factors can affect international students and academic staff together as they cater for their needs. There are numerous studies that have indicated a positive and significant relationship between the organizational performance and diversity (Soni 2000). Furthermore, businesses that include a greater level of diversity have demonstrated a greater impact on organizational commitment (Giffords 2009), together with improved total performance (Sacco and Schmitt 2005). Thus, it can be said that having a proper and adequate system of attracting and recruiting diverse workforce can yield in an increased competitive rivalry for the organization. This becomes vivid in a relatively small island of Cyprus as academic units can be compared in terms of diversity and their performance as well as image can be examined.

Information on the relationship between performance and diversity at universities worldwide that include employees and students from diverse regions in the world still remains limited. Variation in industries in relation to diversity of staff is noticeable and this is even after extensive awareness on the topic has been raised. The subject of inclusion and diversity has generated a focus of interest. Although, the volume of data is excessive, but the amount of activities relating to the topic is barely visible, and though material is widely available, the actions remain outdated. Managers have expressed interest and emphasis relating to inclusion and diversity. This is while directors and board members seem to decline such measures.

Within academic realm of university, when preparation to incorporate diversity is confronted by barriers or confined by politically inappropriate commentary, or support from senior levels is absent, diversity fatigue can occur. As a result, all the endeavor and commentary will serve as a mere propaganda and thereby, making employees and students resent hierarchy, which inevitably generates a sense of distrust, weariness and questioning. This in turn can damage the productivity level of the organization on a significant level as it impacts morale of staff. The resulting diversity fatigue is a critical and vital consequence of an unstable diversity at universities, whereby studies available do not offer measurement scopes to measure within an organization.

Current study by performing a qualitative research among top managers of international universities presented two main different aspects of diversity fatigue for the first time, which can aid managers to avoid such problems regarding diversity among employees. The developed items will be applied also in a quantitative analysis for current study as a negative moderator between diversity and operational performance to 
present its critical role at international universities. It is expected that diversity fatigue exhibits a dampening effect on the relationship between workforce diversity and organizational overall performance.

\section{THEORETICAL BACKGROUND AND HYPOTHESIS DEVELOPMENT}

\subsection{Workforce Diversity and Organizational Performance}

The topic of diversity is understood differently, where there are some who perceive diversity as ideal prospect to improve an organization, and then there is a number who consider that it is simple as a compliance matter which affects legal aspects of business. The subject of diversity is also being considered as a crucial strategic prospect for organizations, thereby enabling managers to encourage diversity for the benefit of performance levels. In an embracing, diverse environment, any number of ideas and suggestions can be highlighted for encouraging enhancement and enablement of the subject under review. As a result, a convivial and open approach offers room for staff to innovate and become creative in the workplace, thereby increasing performance levels (Allen et al. 2007).

Several studies have indicated the rewards that are offered by diversity for a business (e.g. attracting and retaining talent, lower turnover intentions, reduced legal threats, awareness of the market and its relative requirements, greater originality and innovation within the organization, improved problem-solving practices, improved flexibility in the company, heightened decision-making procedures and greater performance levels) (Robinson and Derchant 1997). Comparatively, there has been research indicating that diversity has highlighted a reverse response on the organizational performance, with job-satisfaction and turnover interacting in the equation ( $\mathrm{O}^{\prime}$ Reilly, Caldwell, and Barnett 1989). Furthermore, the negative relationship was discovered with an impression of organizational detachment (Tsui, Egan, and O' Reilly 1992), lower aspects of integration, language barriers, reduced communication and struggles or poor atmospheres within work groups (Richard et al. 2003). All these elements that are mentioned above create a negative impact on the organizational performance.

In the light of the above, further examination of diversity is required as studies have discovered varying results. Discrepancies in previous literature on diversity and the gauging of the phenomenon should be reinvestigated (Harrison and Sin 2006). Definitions on diversity and the related elements in the measurement have been researched by Prasad, Pringle, and Konrad (2006). The differences in descriptions explore the various means to comprehend and scrutinize diversity in the workplace. As a result, this has led to altered classifications of diversity in relation to research. The work of Kossek, Lobel, and Brown (2006) further examines the subject, which includes influences and similarities that occur between workplace diversity and performance of organization together with strategies on HRM. Accordingly, considering previously mentioned elements, the context needs additional investigation.

Research carried out by Kochan et al. (2003) suggested that connection concerning performance and diversity may differ in being affected by factors concerned. The moderating factors and their investigations can assist for an improved comprehension of the relationship. Another opportunity for integrating this topic is to study and focus on the orientations of the business on diversity and focus not solely on one firm and its diversity. Also, to comprehend the deviation that occurs on diversity, understanding of subject matter could be a focus for comprehending causes and results.

The definition of diversity according to Thomas (2003) suggests that it is an accumulation of detectable elements (e.g. race, sex, age) and additional elements, which are not vivid (e.g. educational achievement, sexual orientation, religion, preferences and values). Further terms that can be implemented, suggested by Cox $(1993$, p. 6) is diversity "a mix of people in one social system, who have distinctly different, socially relevant group affiliations". The expansive definition was further extended by Loden (1996), who suggests that diversity is the uniqueness of principles and differences, arriving at an organization with each individual. However, it is noteworthy that due to the complex nature of aforementioned definitions, further examination and investigation is deemed necessary to provide better understanding of this phenomenon.

Evolution of diversity has been characterized in three specific groups, by Thomas (2003), the worldwide market, relating to the motivation behind competitiveness in business; the constantly changing aspects and consistency of the workforce and recruitment (Toosi 2002), and the focus on embracing individual differences as opposed to promotion of them. Accordingly, the advent of diversity points to the fact that diversity is considered an element, which in turn can increase competitiveness and competitive advantage in a market place. To measure the organizational performance involves a number of different elements, which coincidentally affect or have the potential to affect. 
A survey instigated by (Ferguson 2011), commented that tourism is considered to be a gendered area of business. According to (Cho et al. 2017), by increasing the possibility of globalization, diversity of the workforce was one of the most fundamental concerns in an organization. In fact, diversity of the workforce relates directly to equality and intrinsic value that is placed on it (Travis, Lizano, and Mor Barak 2015; Ng and Sears 2012). It is then considered crucial that as result of positive affect of diversity in business environment, employment of enthusiastic diversity approachable staff is critical (Barak, Findler, and Wind 2016).

It would seem obvious that diversity will positively impact on performance of organization (Richard, Roh, and Pieper 2013) together with any number of other constructive effects, including but not limited to, improved organizational obligation (Cho and Mor Barak 2008) and retaining of staff (Hobman, Bordia, and Gallois 2003). It should also be pointed out that studies conducted by Choi and Rainey (2010), documented that diversity could affect adversely organizational performance. Therefore, further studies are required to explore the relationship. Discovering the result of diversity management on organizational performance within workplace is considered to be one of the most fundamental areas of research over the last 10 years (Groeneveld 2011; McKay and Avery 2015; Ng and Sears 2012).

It is crucial to find the correct and most related theory for evaluation of the relationship between workforce diversity and organizational performance. The chosen theory is the optimal distinctiveness theory (Brewer 1991) which addresses team consistency and linking of positive effect on employees' performance in organization. It is further suggested that a significant trial for managers is decreasing conflicts and unfamiliarity of workforce to increase performance. Certainly, the optimal distinctiveness theory attempts to improve organizations culture relating to diversity. It has been stated that members of team desire opportunities to be more similar to the rest of the team (Greenberg, Ashton-James, and Ashkanasy 2007) whilst wanting to retain their own individuality (Brewer 1991). Accordingly, businesses with differing teams and increased diversity try to accomplish an inclusive work atmosphere (Shore et al. 2011) and as a result, they offer an improved organizational performance. Some academics such as, Giffords (2009) suggest that companies with greater diversity demonstrate improved organizational performance and most scholars agree that diversity always leads to greater organizational performance.

In relation to measurement of diversity, Reinforcing Homogeneity (Dass and Parker 1999) and differentiation between Color-Blindness and Fairness will be used in current study. A business with greater diversity is dedicated to bearing in mind gender equality (Thomas 1992). The international universities in Northern Cyprus have considerable scopes of educational tourism, creating employment opportunities for both men and women of varying ages and educational backgrounds. In light of the above and with the extensive review of various theories presented previously, the following hypothesis is emerged:

\section{H1: Workplace diversity has a significant impact on Overall performance.}

\subsection{Educational Toursim in Northern Cyprus}

Over the past few decades, education industry has experienced a rapid rise in numbers of students worldwide (Abubakar, Shneikat, and Oday 2014). According to United Nation's Educational, Scientific and Cultural division as stated that a number in excess of 2.5 million students from around the world were studying overseas during the year 2009, with most of them continuing their education to university level. Educational tourism is not an original subject (Holdnak and Holland 1996). However, the relevance is highlighted by the need for new research. There are direct areas of focus in educational tourism ranging from demographic, socioeconomic, geographic and psychographic (Bhuiyan et al. 2010). The attention of tourism is shifting around the world with significant numbers choosing educational tourism as the main choice to travel abroad (Zarzuela et al. 2013).

Although Northern Cyprus is a small island, it has experienced an unbelievable growth in educational tourism since the 1990's. The volume has been ever increasing due to the incredible demand for higher education coming from Turkey, Africa and Middle East countries (Katircioğlu 2014). Through growing higher educational sector, demand on the island has increased with high quality services being offered by international universities maintaining a competitive edge. Northern Cyprus has shown economic growth through improvement of educational tourism. With educational tourism playing such a vital role on the island, then considerable studies could be implemented to research other aspects. A research carried out by (Katircioğlu 2010) relating to the effect on the economic growth of North Cyprus in relation to effects of educational tourism. It states that there was a significant influx of foreign exchange and employment as a result of educational tourism on this small island. Prior to 1974 , North and South Cyprus were a single entity 
known solely as Cyprus. However, after 1974, it is now part of Turkey.

In relation to significance of diversity and the positive role it has on performance of universities, there are currently no studies. In regard to universities there is no literature which specifically focuses on the impact diversity has on organizational performance. This study aims to contribute to explore the relationship at an international university in Northern Cyprus. There are some well-known international universities based on the island, for example Eastern Mediterranean University, which was ranked within the best $5 \%$ of universities among 25,000 world universities in 2014 recorded by Webometrics Ranking of World Universities (n.d). It was selected as one of the reference case studies due to its 20,000 students from 106 countries, which involve 1,100 academic staff from 35 different countries. This clearly expresses how this international university produced a considerable number of employment opportunities. Other chosen universities are Girne American University, Near East University and Cyprus International University.

\subsection{Diversity fatigue, trust issue, and emotional tiredness}

According to The Economist, diversity can have a negative impact on employees trust level (Diversity Fatigue, 2016). The cause of this could be affected by work environments with high level diversity experiences staff having less in common with their colleagues than in a less diverse workplace (Choi and Rainey 2010). As a result of the abovementioned notion, this could lead to changes in performance of an organization. This research has opened up two prominent dimensions on diversity fatigue within the context of university through applying qualitative analysis by conducting interviews.

H2: Diversity Fatigue suppresses the effect of Worforce Diversity on Overal Performance

\section{METHODOLOGY}

\subsection{Sample and Procedure}

The data for this research was collated through two separate steps from full-time academic and administrative employees, who are working at international universities in North Cyprus.

The judgmental sampling was selected for this research according to the purpose of the study for quantitative analysis. Cyprus is one of the largest islands in the Mediterranean Sea and tourism is the main industry, with educational tourism completely changing its economic progression. There were two separate sections for each employee, where they were asked to answer the questions related to workforce diversity initially and then questions referring to workforce fatigue (emotional tiredness) and their overall performance. As a final stage the responses were collected after two weeks from the selected international universities.

The distribution number was five hundred at the indicated international universities, whereupon four hundred and seventy questionnaires were reached and from this number four hundred and four were accepted. Although the main language of North Cyprus is Turkish, all employees know English extremely well and therefore, no translation was required.

A pilot study was performed at one university to ensure that the questions were understandable for the respondents. In relation to measuring diversity fatigue which was defined in the questionnaires format for the first time, pilot study was performed (32 questionnaires) and the results presented normal distribution and satisfactory validity for constructs.

Suggestions made by Podsakoff et al. (2003), it is better that there will be a temporal separation between the measurements. Thus, the measurement items were answered in two sections. Prior to commencement of the research a meeting was held with the dean and vice dean of each faculty to describe the purpose and procedure of distributing questionnaires amongst employees.

\subsection{Measures}

Workforce diversity (Podsiadlowski et al. 2013) by measuring three different aspects namely reinforcing homogeneity, Color-Blind and Fairness totally measured 10 items. As it was defined in qualitative analysis section, diversity fatigue's items were developed through interviews. The items were categorized in two different dimensions namely, trust issue, and emotional tiredness. All items of diversity fatigue and emotional tiredness in the questionnaire are measured on a 5 -point Likert scale ( 1 = strongly disagree; 5 =strongly agree). Implementing the scale developed by the work of Dess and Robinson (1984), staff were questioned about the extent of competitiveness of their firm in comparison with other competitors within the period of three years based on a six dimension variable (quality, productivity, profitability, market share, return on equity, and overall performance). Construct items have been transformed into variables through mean for testing the variable as whole. The 
aforementioned variables are more likely to represent a proper answer if conducted on objectively chosen financial and/or production data, which was out of the boundaries of this particular research and is explained in the limitations section.

\subsection{Qualitative Analysis of Diversity Fatigue Dimensions}

Five semi-structured interviews were conducted with senior-level executives (two women and three men) who worked in a range of diverse organizations for more than 20 years. The interviewees aimed at exploring their views and experiences on diversity in order to identify the emerging forms of diversity fatigue they experienced at their workplaces. These findings later utilized and incorporated in developing the diversity fatigue dimension of the questionnaire.

All the interviewees considered diversity as "the norm" or "essential part of modern day workplace" in a globalized world of work.

- In today's global economy it has become the norm. (Interview Question 1, Female)

- Personally, I feel diversity is very important. I worked in a global business and it was essential to embrace cultural traditions and ideas...I think embracing people's abilities not their race, gender or sexual orientation is nothing but a strength to any organisation (Interview Question 4, Male)

- I feel that we should learn to get on with it as this is now the $21^{\text {st }}$ century and like it or not diversity is here to stay. (Interview Question 5, Male)

They believed that all organizations, based on their size, had to make adjustments to ensure that the needs of the diverse workforce would be fulfilled. The possible measures suggested by the interviewees varied from introducing workplace training on basic understandings of different cultures to ensuring special needs of the workforce is considered.

- Part of the workplace training should be teaching a basic understanding of cultures, nations, religious beliefs, business etiquette, acceptable male-female interaction, traditions, what is considered polite impolite and sometimes it is a simple as what foods to serve during a training session. For example, during linguist training on a Military Base in the US, participants where $90 \%$ were Muslim, $90 \%$ of the prepared meals for lunch and dinner contained pork and the privacy concerns for females in the group were not considered as a result the day of training was not very successful. (Interview Question 1, Female)

- I enjoy working in a diverse workplace as it has allowed me to meet and understand other beliefs' and cultures and broadened my learning areas. Diverse attitudes can be improved by holding regular open meetings with management and staff where everyone is encouraged and allowed to voice their opinions, concerns and experiences so that all can understand the issues. (Interview Question 2, Male)

- An organisation can listen to its' staff more, listen what the workforce want rather than do what you think they want. (Interview Question 3, Female)

The existing theory which is discussed in the literature review and qualitative interviews were utilized for developing the two dimensions of the diversity fatigue, namely trust and emotional tiredness.

\subsubsection{Trust Issue}

Based on the common themes that emerged from qualitative interviews: Trust dimension involved not only the idea of being trusted by their colleagues, but also having different abilities in understanding the responsibilities of the work. This created tiredness through generating concerns over colleagues' abilities to complete the tasks/being able to trust the team members to complete the task, and increased the chances of work-related misunderstandings between the colleagues. For example interviewer 1 mentioned the need for extra effort including confirmations and employing different approaches or making allowances in order to make things work, which can become a source of diversity fatigue.

- In the beginning I used to assume a lot and realized quickly that sending and receiving was not always the same, so now I usually ask staff to confirm to me either via email or conversation, how they understood or how they are approaching a task. It also teaches you that different approaches work and that you need to apply different parameters and deadlines if you need something to work. With all things being equal, you need to be able to make allowance in a diverse environment regarding people's background, experience (work) and ability to approach a task and possible language differences or interpretation. It is sometimes impossible to be fair in all situations, however you need to respectful when discussing issues and concerns. (Interview Question 1, Female)

- The only downside is it can slow the process down if your partner does not share and understand the cultural norms. One barrier to understanding is of course language competency. My global 
experience has met many levels of language abilities and training is important especially around language in a global business; it is difficult to promote someone who cannot communicate with fellow employees. (Interview Question 4, Male)

Some of the interviewees believed that diversity could be used as a source of discrimination if used for gaining better positions/working conditions.

- Diversity is used as a tool or threat for an individual to gain better working conditions or to hide poor performance issues. (Interview Question 2, Male)

- Some people can use diversity to gain favour. (Interview Question 3, Female)

- People are there to work for a living and should conform with the employers directives, not to use ethnic race card to get out of what you are paid and employed to do. (Interview Question 5, Male)

\subsubsection{Emotional Tiredness}

Emotional Tiredness included worries about trying not to offend colleagues who belong to the 'other' groups (beliefs, life styles, racial, religious, gender etc.). This required a constant need for trying to be politically correct around the colleagues with diverse backgrounds.

- Language and localised sayings can be a problem. I have witnessed a person from one area of England make a comment to a black woman which in his part of the country was considered a complement and was received in this way. However, this was witnessed by a third party where in their part of the country it was deemed a racist insult and this person made a complaint resulting in an investigation. (Interview Question 2, Male)

- Being politically correct around your diverse colleagues in my opinion has got so far out of hand people are actually stopping talking to each other in fear of reprisal. (Interview Question 5, Male)
Please note: The interview questions are attached as Appendix I.

By relying on moderating role of both aspects of diversity fatigue on the relationship between workforce diversity and overall performance the following hypotheses could be developed:

\section{DATA ANALYSIS}

Data analyses for this study will describe geographical profile of respondents and exploratory and confirmatory factor analysis. The internal consistency reliability was assessed based on the commonly accepted cut-off value of 0.70 (Nunnally 1978). SPSS Version 22 was used to analyze moderating effect of diversity fatigue on relation between workforce diversity and overall performance. The hypothesized model of moderating role of emotional tiredness and trust issue in the relationship between workforce diversity and overall performance is presented in Figure 1.

\subsection{Profile}

First table shows itemization of the collected sample. Specifically, $9 \%$ of respondents were aged between 18 and 27 years and $31 \%$ of respondents were aged between 28 and 37 . Fifty-six percent were aged between 38 and 47 and the rest were older than 47 . As table1 represents, the sample consisted of equal male and female $(50 \%)$ respondents. Regarding educational career, as figures demonstrate $52 \%$ had $\mathrm{PhD}$ degrees. About organizational tenure $4 \%$ of employees had less than one-year work experience at university and $3 \%$ had 1-5-year work experience. Thirty- Five percent were with university about 6-10 years and $40 \%$ had 11-15-year work experience. The rest were more than 15 years in the related university. Single people almost include the majority of the respondents, as $52 \%$ and remain (48\%) were Married.

Figure 1. Theoretical Model

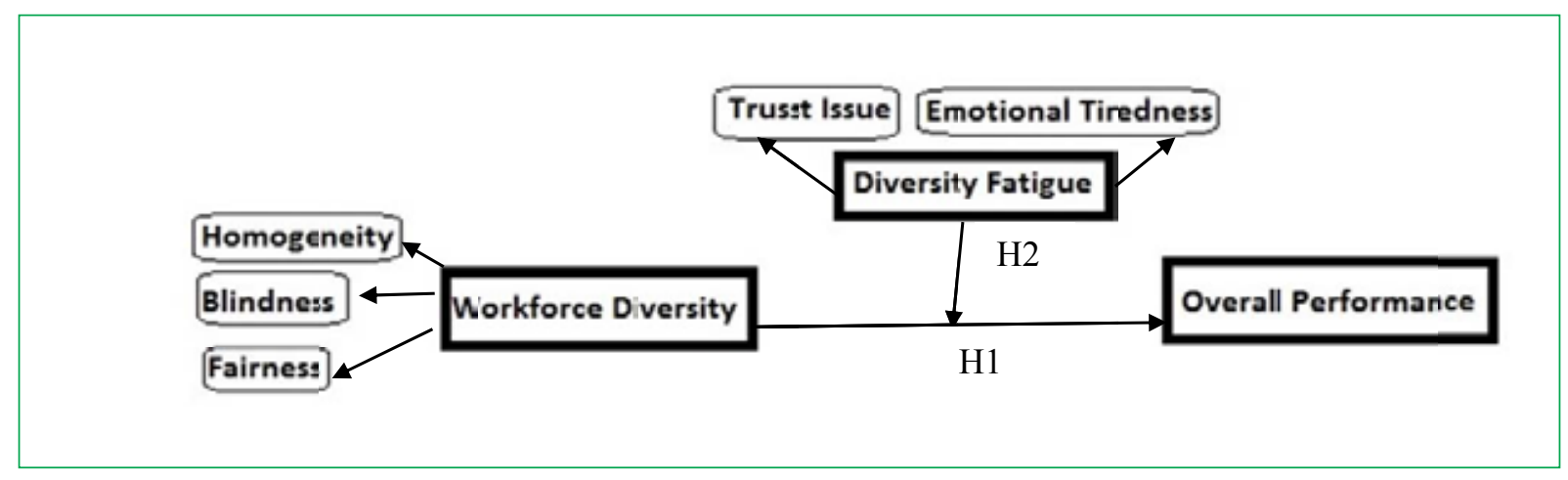


Table 1. Respondents' Profile

\begin{tabular}{|c|c|c|}
\hline Respondents' Profile & Frequency & Percentage \\
\hline \multicolumn{3}{|l|}{ Age } \\
\hline $18-27$ & 35 & 9 \\
\hline $28-37$ & 126 & 31 \\
\hline $38-47$ & 226 & 56 \\
\hline $47-58$ & 2 & 1 \\
\hline $58-67$ & 15 & 4 \\
\hline Total & 404 & 100 \\
\hline \multicolumn{3}{|l|}{ Gender } \\
\hline Male & 203 & 50 \\
\hline Female & 201 & 50 \\
\hline Total & 404 & 100 \\
\hline \multicolumn{3}{|l|}{ Education } \\
\hline Undergraduate & 26 & 6 \\
\hline Vocational school & 37 & 9 \\
\hline Master & 132 & 33 \\
\hline $\mathrm{PhD}$ & 209 & 52 \\
\hline Total & 404 & 100 \\
\hline \multicolumn{3}{|l|}{ Organization tenure } \\
\hline Under 1 year & 15 & 4 \\
\hline $1-5$ years & 11 & 3 \\
\hline 6-10 years & 140 & 35 \\
\hline 11-15 years & 163 & 40 \\
\hline $16-20$ years & 75 & 18 \\
\hline Total & 404 & 100 \\
\hline \multicolumn{3}{|l|}{ Marital status } \\
\hline Single or divorced & 209 & 52 \\
\hline Married & 195 & 48 \\
\hline Total & 404 & 100 \\
\hline
\end{tabular}

Additionally, the respondents were chosen in a manner to exhibit diversity within the workforce of selected universities. Based on collected data, our respondents were from an array of countries that are namely, Turkey, Cyprus, Iran, Iraq, Jordan, Kazakhstan, Russia, Ukraine, USA, UK, Congolese, Nigeria, Kenya, Azerbaijan, Turkmenistan, Syria, Palestine, Libya, Tunisia and Morocco. The research team emphasized on selection of respondents and to ensure representation of diversity among the participants. As previously mentioned, universities selected for our research had a diverse workforce as they are international organizations. Thus, throughout the data collection process, our research team ensured participants are chosen regarding their various nationalities, and that diversity measures are taken into account.
Specifically, coefficient alpha for workforce diversity, diversity fatigue and overall performance were $0.88,0.88$, and 0.87 . The results signify that all coefficient alpha scores were greater than the accepted cutvalue of 0.70 (Nunnaly 1987) and all measures were reliable.

Referring to table 3 of this paper, it can be seen that through various regression models, the workforce diversity (WD) and its relationship with Overall performance has been moderated by Diversity Fatigue (DF) $(r=-0.021)$. However, the interaction plot exhibits this statement on a more profound manner. It can be seen that respondents with higher diversity fatigue levels (trust issues or emotional tiredness) and low WD have shown a lower rate regarding their overall performance. This is while when DF has been reported poor, and WD has been high, the overall performance has a tendency to be increased. The effects of Diversity fatigue due their negativity have been reported as "dampening" or "suppressing", which means the variable implies a depressing effect on the existing relationship between the two dependent and independent variables (Jose 2013; Rose et al. 2004). In other words, the positive variables (WD and OP) have faced a dampening effect with inclusion of DF. This supports our hypothesis of moderation $(\mathrm{H} 2)$. Our results also demonstrate that workforce diversity and its characteristics have a significant relation with overall performance, which supports our first hypothesis. However, consisting Emotional Tiredness and Trust Issues as negative moderators (which are shown as Diversity Fatigue) within the equation has led to a higher level of significance, which cannot be neglected. Ergo, it can be stated that moderation has also taken place within the above relationship. Main purpose of this study was to analyze moderating role of emotional tiredness (an important part of diversity fatigue) alongside trust issues on the relation between workforce diversity and overall performance. This moderation was found to be of negative value, which was expected as higher levels of emotional tiredness and trust issues logically affect the overall performance level in a negative manner. Our results support our hypotheses regarding both positive relationship between workforce diversity (Reinforcing Homogeneity, Color blind, and fairness) and Overall performance. Furthermore, our results also show the occurrence of moderation effect from Diversity Fatigue (Emotional Tiredness and Trust Issues) on the relationship between Workforce Diversity and Overall Performance. This is in consensus with prior studies on the matter as well as being intact with qualitative measure of current study. 
Table 2. Factor Loadings and Construct Reliability

\begin{tabular}{|c|c|c|c|c|}
\hline & $\mathrm{FL}$ & CR & a & AVE \\
\hline Reinforce Homogeneity & & 0.85 & 0.84 & 0.585 \\
\hline We are striving for a homogeneous workforce & 0.781 & & & \\
\hline It feels better to work with similar others & 0.799 & & & \\
\hline $\begin{array}{l}\text { People fit into our organization when they are similar to our already existing } \\
\text { workforce. }\end{array}$ & 0.784 & & & \\
\hline Through similarities we feel more connected as colleagues & 0.754 & & & \\
\hline Color Blindness & & 0.84 & 0.81 & 0.590 \\
\hline Qualification matters in our organization, not background & 0.841 & & & \\
\hline $\begin{array}{c}\text { Promotion is dependent upon employee performance, not on someone's } \\
\text { background }\end{array}$ & 0.687 & & & \\
\hline All are welcome as long as they meet the necessary requirements & 0.745 & & & \\
\hline People fit into our organization when they match the required job qualifications & 0.811 & & & \\
\hline Fairness & & 0.79 & 0.85 & 0.623 \\
\hline $\begin{array}{l}\text { We regard it as important to give employees from disadvantaged groups specific } \\
\text { support for their further development }\end{array}$ & 0.846 & & & \\
\hline $\begin{array}{c}\text { Our organization is culturally diverse, as we take equal employment opportunities } \\
\text { seriously }\end{array}$ & 0.648 & & & \\
\hline $\begin{array}{l}\text { People fit into our organization when they reflect the demographics of the society } \\
\text { we are situated in }\end{array}$ & 0.712 & & & \\
\hline People from all societal groups have equal chance of being recruited in our firm & 0.723 & & & \\
\hline Trust Issues & & 0.86 & 0.88 & 0.582 \\
\hline I do not feel that I am trusted by my colleagues & 0.649 & & & \\
\hline I am not confident in the other group members ability to help me & 0.822 & & & \\
\hline The other group members do not understand my point of view & 0.749 & & & \\
\hline I feel like the organization prefers some people to others due to diversity & 0.731 & & & \\
\hline Emotional Tiredness & & 0.78 & 0.86 & 0.501 \\
\hline $\begin{array}{l}\text { I am exhausted of being afraid to offend the other team members who have differ- } \\
\text { ent ideas, beliefs and life style }\end{array}$ & 0.658 & & & \\
\hline $\begin{array}{l}\text { do not feel comfortable that the organization, I work for, keeps supporting others } \\
\text { with different ideas and beliefs }\end{array}$ & 0.710 & & & \\
\hline I am tired of being politely correct all the time & 0.649 & & & \\
\hline
\end{tabular}

Table 3. Different Regression Models for Estimation of Overall Performance

\begin{tabular}{|c|c|c|c|c|c|}
\hline & & Coeff. & SE & $t$ & $p$ \\
\hline \multirow[b]{2}{*}{$\begin{array}{l}\text { Model } 1 \\
(\mathrm{R}-\mathrm{sq}=0.092 \\
\mathrm{MSE}=0.782)\end{array}$} & Constant & 3.431 & 0.412 & 12.544 & $<0.001$ \\
\hline & WD & 0.162 & 0.031 & 2.392 & $<0.001$ \\
\hline \multirow{3}{*}{$\begin{array}{l}\text { Model } 2 \\
(\mathrm{R}-\mathrm{sq}=0.223 \\
\text { MSE }=0.691)\end{array}$} & Constant & 2.752 & 0.641 & 8.145 & 0.013 \\
\hline & WD & 0.147 & 0.412 & 4.129 & $<0.001$ \\
\hline & DF & -0.434 & 0.138 & -3.213 & $<0.001$ \\
\hline \multirow{4}{*}{$\begin{array}{l}\text { Model } 3 \\
(\mathrm{R}-\mathrm{sq}=0.411 \\
\mathrm{MSE}=0.586)\end{array}$} & Constant & 3.146 & 0.632 & 3.926 & $<0.001$ \\
\hline & WD & 0.541 & 0.176 & 3.186 & $<0.001$ \\
\hline & DF & 0.118 & 0.058 & 0.965 & 0.021 \\
\hline & WD $\times$ DF & -0.021 & 0.007 & -2.541 & $<0.001$ \\
\hline
\end{tabular}


Table 4. Additional Statistical Outputs for Plotting the Interaction

\begin{tabular}{lcc}
\hline Variable & Mean & $\begin{array}{c}\text { Standard } \\
\text { deviation }\end{array}$ \\
\hline Workforce Diversity & 31.1512 & 11.2177 \\
\hline Diversity Fatigue & 14.9786 & 8.2882 \\
\hline
\end{tabular}

Figure 2. Interaction Plot of Moderation Effect

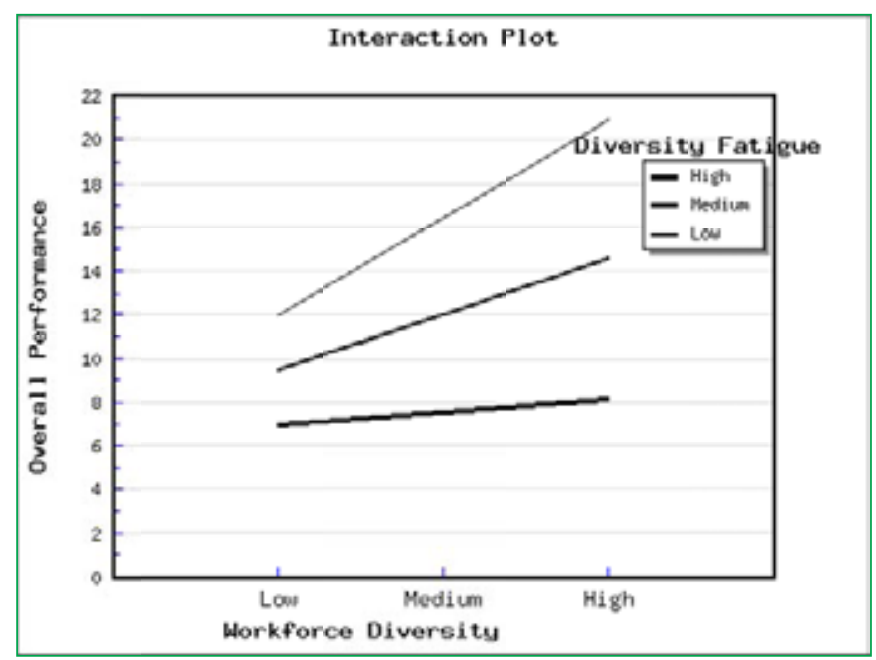

\section{DISCUSSION}

\subsection{Evaluation of Findings}

The main determination of this study was to investigate the moderating role of emotional tiredness in the relationship between workforce diversity and overall performance within the context of international universities situated in North Cyprus. The study was conducted through measuring the variables under examination through questionnaire surveys together with interviews. Hypotheses in this article, demonstrate that workforce diversity has significant relationship with overall performance. This is while diversity fatigue has a dampening impact on the overall performance and workforce diversity, based on the results of this study. This demonstrates the fact that there is existence of emotional tiredness and trust issues can extremely negatively impact the relationship between workforce diversity and organizational performance, which in turn can be costly for the organization. The strength becomes more apparent within an atmosphere such as universities where the level of diversity is comparatively higher. Therefore, the relevance of suppressing effects of diversity fatigue must not be neglected.

\section{IMPLICATIONS}

\subsection{Theoretical Implications}

Theoretically, this paper was instigated to examine the effect of workforce diversity on emotional tiredness and overall performance. There is no study that have surveyed the effect of workforce diversity on overall performance, by moderating role of emotional tiredness alongside trust issues by using optimal distinctiveness theory. This makes the contributions of this research twofold. As our theoretical model has not been investigated prior to this research, the literature can only expand through this model. Additionally, managerial implications, which arise from our results, are another contribution, which are explained further in this section.

\subsection{Managerial Implications}

In light of the results of this research, it can be noted that diversity within workforce can have positive outcomes and have a direct and yet significant impact on overall performance of the organization. It carries vitality to consider that the previously indicated findings are in fact an integral of other variables, which can be influential (e.g. diversity fatigue). Through the accuracy of this study, diversity fatigue, whilst not having significance on overall performance on an individual basis, has intense impacts on overall performance when it is within the context of workforce diversity. This can act as an indicator for managers as diverse work environments require constant care and supervision relating to diversity fatigue, to properly and positively affect overall performance of the organization in both short-term and long-term basis. Furthermore, having considered trust and emotional tiredness, managers within organizations can achieve improved levels of performance for an organization, if trust is generated through an environment of preservation and equality. Within a workplace of a diverse nature, employees need correct managing and leadership to demonstrate the opportunities during difficult times and also to allow them to focus on achieving the organizational goals and objectives.

\section{LIMITATIONS AND SUGGESTIONS FOR FUTURE STUDY}

As with most researches, this research has experienced restrictions and limitations for conducting the study. The most prominent limitation was that of financial support for the study. With papers of this 
scale, involving several aspects being under examination and mixed processes of analysis, necessitate support which was not forthcoming for this research. Furthermore, the restrictions on time due to university lives, more specifically the availability of suitable members for the research, this research was limited to restrictive dates, and to be merged within a limited time-bound. Objectivity of financial and/or production data available for this study, specifically in relation to variables under examination in terms of competitiveness and extent of rivalry within the market was another limitation, which restricted the research. With such data it would permit the team of researchers to possess more full and sufficient overview on the subject of competitiveness in the market space, thereby creating an improved understanding of the relevant variables. Furthermore, this study was restricted to research conducted within international universities in Cyprus therefore a cross-cultural survey could lead to a more comprehensive understanding of the phenomenon. It should also be noted that if a study were to be carried out in neighboring countries like the Middle East or Mediterranean, the results could have brought generalization on understanding differences. As diversity is a literal application of differing backgrounds and cultures within a specific environment, similar research with different contexts can create better understanding on the subject matter. Accordingly, a cross-sectional study, comprising of different industries or different divisions could be examined (i.e. tourism/hotels, local firms, banking) can aid in the process of understanding the topic.

\section{REFERENCES}

Abubakar, A. M., Shneikat, B. H. T., \& Oday, A. 2014. Motivational factors for educational tourism: A case study in Northern Cyprus. Tourism Management Perspectives, 11, 58-62.

Allen, R. S., Dawson, G., Wheatley, K., \& White, C. S. 2007. Perceived diversity and organizational performance. Employee Relations, 30(1), 20-33.

Barak, M. E. M., Findler, L., \& Wind, L. H. 2016. Diversity, inclusion, and commitment in organizations: International empirical explorations. Journal of Behavioral and Applied Management, 2(2), 813.

Bhuiyan, M. A. H., Islam, R., Siwar, C., \& Ismail, S. M. 2010. Educational tourism and forest conservation: Diversification for child education. Procedia-Social and Behavioral Sciences, 7, 19-23.

Brewer, M. B. 1991. The social self: On being the same and different at the same time. Personality and social psychology bulletin, 17(5), 475-482.
Cho, D. H., Choi, J. W., Kang, Z., Kim, B. H., Oh, H. M., Kim, H. S., \& Ramanan, R. 2017. Microalgal diversity fosters stable biomass productivity in open ponds treating wastewater. Scientific Reports, 7(1), 1979.

Cho, S., \& Mor Barak, M. E. 2008. Understanding of diversity and inclusion in a perceived homogeneous culture: $\mathrm{A}$ study of organizational commitment and job performance among Korean employees. Administration in Social Work, 32(4), 100-126.

Choi, S., \& Rainey, H. G. 2010. Managing diversity in U.S. federal agencies: Effects of diversity and diversity management on employee perceptions of organizational performance. Public Administration Review, 70, 109-121.

Cox, T. 1993, Cultural Diversity in Organizations: Theory, Research, and Practice, Berrett-Koehler, San Francisco, CA.

Dass, P., \& Parker, B. 1999. Strategies for managing human resource diversity: From resistance to learning. Academy of Management Perspectives, 13(2), 68-80.

Dess, G. G., \& Robinson Jr, R. B. 1984. Measuring organizational performance in the absence of objective measures: the case of the privately-held firm and conglomerate business unit. Strategic management journal, 5(3), 265-273.

Diversity fatigue. 2016. Making the most of workplace diversity requires hard work as well as good intentions. The Economist. From https://www.economist.com/business/2016/02/11/diversity-fatigue (accessed September 12, 2019).

Ferguson, L. 2011. Promoting gender equality and empowering women? Tourism and the third Millennium Development Goal. Current Issues in Tourism, 14(3), 235-249.

Giffords, E. D. 2009. An examination of organizational commitment and professional commitment and the relationship to work environment, demographic and organizational factors. Journal of Social Work, 9(4), 386-404.

Greenberg, J., Ashton-James, C. E., \& Ashkanasy, N. M. 2007. Social comparison processes in organizations. Organizational Behavior and Human Decision Processes, 102(1), 22-41.

Groeneveld, S. 2011. Diversity and employee turnover in the Dutch public sector: Does diversity management make a difference? International Journal of Public Sector Management, 24, 594-612.

Harrison, D. A., \& Sin, H. 2006. What is diversity and how should it be measured. Handbook of workplace diversity, 191-216.

Hobman, E. V., Bordia, P., \& Gallois, C. 2003. Consequences of feeling dissimilar from others in a work team. Journal of Business and Psychology, 17(3), 301-325.

Holdnak, A., \& Holland, S. M. 1996. Edu-tourism: Vacationing to learn. Parks and Recreation, 31(9), 72-75. 
Jose, P. E. 2013. Doing statistical mediation and moderation. Guilford Press.

Katircioğlu, S. T. 2010. International tourism, higher education, and economic growth: The case of North Cyprus. The World Economy, 33(12), 1955-1972.

Katircioğlu, S. T. 2014. Estimating higher education induced energy consumption: The case of Northern Cyprus. Energy, 66, 831-838.

Kochan, T., Bezrukova, K., Ely, R., Jackson, S., Joshi, A., Jehn, K. \& Thomas, D. 2003. The effects of diversity on business performance: Report of the diversity research network. Human Resource Management: Published in Cooperation with the School of Business Administration, The University of Michigan and in alliance with the Society of Human Resources Management, 42(1), 3-21.

Kossek, E. E., Lobel, S. A., \& Brown, J. 2006. Human resource strategies to manage workforce diversity. Handbook of workplace diversity, 53-74.

Kreitz, P. A. 2008. Best practices for managing organizational diversity. The Journal of Academic Librarianship, 34(2), 101-120.

Loden, M. 1996. Implementing Diversity, Irwin Professional Publishing, Chicago, IL.

McKay, P. F., \& Avery, D. R. 2015. Diversity climate in organizations: Current wisdom and domains of uncertainty. In M. R. Buckley, J. R. B. Halbesleben, \& A. R. Wheeler (Eds.), Research in personnel and human resources management (pp. 191-233). Bingley, UK: Emerald Group Publishing Ltd.

McKay, P. F., Avery, D. R., \& Morris, M. A. 2009. A Tale of two climates: Diversity climate from subordinates' and managers' perspectives and their role in store unit sales performance. Personnel Psychology, 62(4), 767-791.

$\mathrm{Ng}$, E. S., \& Sears, G. J. 2012. CEO leadership styles and the implementation of organizational diversity practices: Moderating effects of social values and age. Journal of Business Ethics, 105(1), 41-52.

Nunnally, J.C. 1987. Psychometric theory. New york: McGraw Hill.

O'Reilly , C. A., Caldwell, D. F., \& Barnett, W. P. 1989. Work group demography, social integration, and turnover. Administrative science quarterly, 21-37.

Podsakoff, P. M., MacKenzie, S. B., Lee, J. Y., \& Podsakoff, N. P. 2003. Common method biases in behavioral research: $A$ critical review of the literature and recommended remedies. Journal of applied psychology, 88(5), 879.

Podsiadlowski, A., Gröschke, D., Kogler, M., Springer, C., \& Van Der Zee, K. 2013. Managing a culturally diverse workforce: Diversity perspectives in organizations. International Journal of Intercultural Relations, 37(2), 159-175.

Prasad, P., Pringle, J. K., \& Konrad, A. M. 2006. Examining the contours of workplace diversity. Handbook of workplace diversity, 1-22.
Richard, O. C., \& Johnson, N. B. 2001. Understanding the impact of human resource diversity practices on firm performance. Journal of Managerial Issues, 13(2), 177-195.

Richard, O. C., Roh, H., \& Pieper, J. R. 2013. The link between diversity and equality management practice bundles and racial diversity in the managerial ranks: Does firm size matter?. Human Resource Management, 52(2), 215-242.

Richard, O., McMillan, A., Chadwick, K., \& Dwyer, S. 2003. Employing an innovation strategy in racially diverse workforces: Effects on firm performance. Group \& Organization Management, 28(1), 107-126.

Robinson, G., \& Dechant, K. 1997. Building a business case for diversity. Academy of Management Perspectives, 11(3), 21-31.

Rose, B., Holmbeck, G., Coakley, R., \& Franks, E. 2004. Mediator and moderator effects in developmental and behavioral pediatric research. Journal of Developmental and Behavioral Pediatrics, 25, 58-67.

Sacco, J. M., \& Schmitt, N. 2005. A dynamic multilevel model of demographic diversity and misfit effects. Journal of Applied Psychology, 90(2), 203.

Shore, L. M., Randel, A. E., Chung, B. G., Dean, M. A., Holcombe Ehrhart, K., \& Singh, G. 2011. Inclusion and diversity in work groups: A review and model for future research. Journal of Management, 37(4), 1262-1289.

Soni, V. 2000. A twenty-first-century reception for diversity in the public sector: a case study. Public Administration Review, 60(5), 395-408.

Thomas, D. 2003, "The effects of diversity on business performance: report of the diversity research network", Human Resource Management, Vol. 42 No. 1, pp. 3-21.

Thomas, R. 1992. Beyond race and gender: Unleashing the power of your total workforce by managing diversity. Amacom.

Toosi, M. 2002, "A century of change: the US labor force", Monthly Labor Review, May, pp. 15-28.

Travis, D. J., Lizano, E. L., \& Mor Barak, M. E. 2015. 'I'm so stressed!': A longitudinal model of stress, burnout and engagement among social workers in child welfare settings. The British Journal of Social Work, 46(4), 1076-1095.

Tsui, A. S., Egan, T. D., \& O'Reilly III, C. A. 1992. Being different: Relational demography and organizational attachment. Administrative science quarterly, 549-579.

Webometrics Ranking of World Universities. n.d. http:// www.webometrics.info/en (accessed September 12, 2019).

Zarzuela, M. M., Pernas, F. J. D., Calzón, S. M., Ortega, D. G., \& Rodríguez, M. A. (2013). Educational tourism through a virtual reality platform. Procedia Computer Science, 25, 382-388. 
Appendix I

\section{Interview Questions}

1. I do not feel that I am trusted by my colleagues

$\begin{array}{lllll}\text { Strongly Disagree } & \text { Disagree }\end{array} \quad$ Undecided $\square \quad$ Agree $\square \quad$ Strongly Agree $\square$

2. I am not confident in the other group members ability to help me

$\begin{array}{llll}\text { Strongly Disagree } & \text { Disagree }\end{array} \quad$ Undecided $\square \quad$ Agree $\square \quad$ Strongly Agree $\square$

3. The other group members do not understand my point of view

Strongly Disagree $\square \quad$ Disagree $\square \quad$ Undecided $\square$

Agree $\square \quad$ Strongly Agree $\square$

4. I feel like the organization prefers some people to others due to diversity

$\begin{array}{lllll}\text { Strongly Disagree } & \text { Disagree }\end{array} \quad$ Undecided $\square \quad$ Agree $\square \quad$ Strongly Agree $\square$

5. I am exhausted of being afraid to offend the other team members who have different ideas, beliefs and life style $\begin{array}{lllll}\text { Strongly Disagree } & \text { Disagree }\end{array} \quad$ Undecided $\square \quad$ Agree $\square \quad$ Strongly Agree $\square$

6. I do not feel comfortable that the organization, I work for, keeps supporting others with different ideas and beliefs $\begin{array}{lllll}\text { Strongly Disagree } & \text { Disagree }\end{array} \quad$ Undecided $\square \quad$ Agree $\square \quad$ Strongly Agree $\square$

7. I am tired of being politely correct all the time

$\begin{array}{llll}\text { Strongly Disagree } & \text { Disagree }\end{array} \quad$ Undecided $\square \quad$ Agree $\square \quad$ Strongly Agree $\square$

